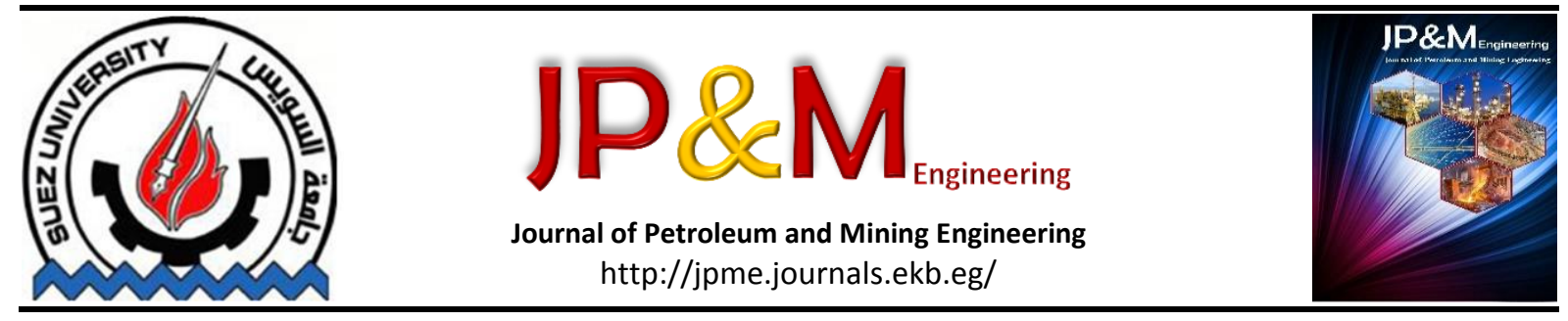

\title{
Determination of Average Reservoir Pressure using Pressure buildup Test: Analytical and Simulation Approach for Egyptian Oil Fields
}

\author{
Adel M. Salem \\ Suez University, Faculty of Petroleum and Mining Engineering, \\ Petroleum Engineering Department, Suez, Egypt \\ *Corresponding author e-mail: adel.salem@suezuni.edu.eg and adel.salem@yahoo.com
}

\section{Keywords}

Average Reservoir Pressure; Buildup test; $\mathrm{MBH}$; $\mathrm{MDH}$; Ramey-Cobb; Dietz Method.

\begin{abstract}
Pressure buildup test is one of the main pressure transient analyses that offers so many parameters that help for reservoir optimization, characterization, and material balance calculations. One of the main objectives of pressure buildup is to determine the average reservoir pressure in the drainage area. Several approaches used to get it. They are Horner, Arps and Smith, MDH, MBH, and Muskat extended methods. This paper compares between all these and investigate the differences and the domain of the applications using several field examples taken from Egyptian fields. After that, a simulation study for these field cases has been performed using Saphir software. Wells drilled in Bayahria formation (Egypt) have been chosen from this study and the recorded tests were analyzed by all methods along with Saphir software. The range of the reservoir pressure is above 2200 psi. The accuracy of each method is calculated. The lowest error method is Arps and smith, Muskat and MBH methods in the first case (the error is less than 1.2\%) and $\mathrm{MBH}$ and $\mathrm{MDH}$ in the second case since the error percentage is less than $4 \%$. Ramey-Cobb method is having the highest error in both cases. The accuracy measurement of reservoir pressure is very beneficial not only in the current reservoir calculation but also for the future calculation and field development plan such as water flowing and enhanced oil recovery. This study represents a road map for using such methods for reservoir pressure calculation for

the Egyptian oil fields.
\end{abstract}

\section{Introduction}

The average pressure in the drainage area of a well represents the driving force for fluid Flow, therefore estimating such pressure is very crucial for any reservoir either oil or gas. Determining average reservoir pressure from pressure transient well testing analysis is vitally important and must be adjusted in order to be used for any further calculations such as material balance calculation, production engineering, reservoir development plan, well performance optimization, water flooding evaluation, various Enhanced Oil Recovery (EOR) processes and pressure maintenance projects, and compute rock and fluid characteristics[1]-[3].

The conventional methods for estimating average reservoir pressure do not only require a prior knowledge of shape factor, but also result in lost production. Consequently, there have been attempts to estimate average reservoir pressure without shutting in wells.

Horner in his papers "Pressure Build-Up in Wells" (1951) [[4], [5]] presented a new method for analyzing the pressure build up test and determining permeability and reservoir pressure in case of a new well far from any reservoir boundary, a new well close to a fault, but far from any other boundary, i.e. a well in a finite reservoir. In his pressure build-up example of a well in a finite reservoir, He differentiated between three different reservoir pressures which are probable pressure (Final closed-in static pressure inthe well), calculated pressure, and false extrapolated pressure $\left(P^{*}\right)$ regarding to reservoir pressure (Figure $1)$.

Later on, it is proved that for a well in a new reservoir with negligible pressure depletion, extrapolation of buildup-test data to infinite shut-in time, $\left(t_{p}+\Delta \mathrm{t}\right) / \Delta \mathrm{t}=1$, on a Homer semilog plot provides an estimate of original (and current) drainage- area pressure [3].

For a well in a reservoir in which the average pressure has declined from its original value because of fluid production, the pressure extrapolated to infinite shut-in time is called $p^{*}$, which is related, but not equal to the current average pressure in the drainage area of the well. 


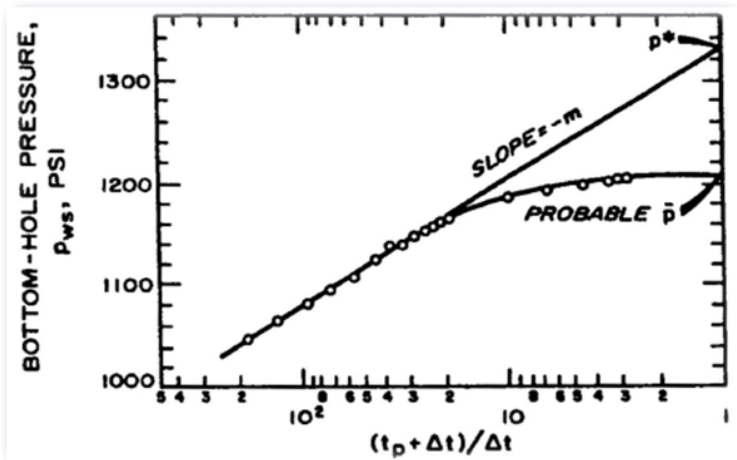

Figure 1 Well shut-in pressure vs. Horner time ratio for buildup testing [6].

\section{Modified Muskat Method:}

In 1949, Muskat [7] provided a modified method for determining average pressure in the drainage area. The modified Muskat method is established on the solution to flow equation for a well producing from a closed, constant rate well in order to determine the reservoir pressure. Muskat indicated that a plot of $\log \left(\bar{P}-\mathrm{P}_{\mathrm{ws}}\right)$ versus $\Delta \mathrm{t}$ should provide a straight line that can be used to calculate $\bar{P}$ as shown in Figure 2. The method also needs that $\Delta t$ and its corresponding $\mathrm{P}_{\mathrm{ws}}$ value should be chosen in the range given by relationship:

$\frac{250 \phi \mu C_{t} r_{e}^{2}}{k} \leq \Delta t \leq \frac{750 \phi \mu C_{t} r_{e}^{2}}{k}$

The equation used in Muskat method is written as follow:

$\log \left(\bar{P}-P_{w s}\right)=A+B \Delta t$

Eqn. 2

Where $\mathrm{A}$ is the intercept of the $\log \left(\bar{P}-P_{w s}\right)$ vs. $\Delta \mathrm{t}$ relationship, and $B$ is the slope of the straight line. Thus, late-time, rather than middle-time, data are essential for this technique. To catch $\bar{P}$, make an initial guess of $\bar{P}$ and plot $\log \left(\bar{P}-P_{\text {ws }}\right)$ vs. $\Delta$ t. Numerous values of $\bar{P}$ are selected until a straight line relationship is reached. The value of $\bar{P}$ that yields a straight line is the precise average reservoir pressure [6].

The Muskat method is quite sensitive. It gives satisfactory $\bar{P}$ value for hydraulically fractured wells, and no crossflow occurs between the layers. The well should be centered in its drainage area. In some cases, the $\Delta \mathrm{t}$ range given above may take long shut-in times for the straight line to develop, particularly when dealing with low-permeability reservoirs [2].

\section{Arps and Smith Method:}

In 1949, Arps and Smith method [8] extended Muskat method. They proposed plotting of $\partial \mathrm{P}_{\mathrm{ws}} / \partial \mathrm{t}$ versus Pws during the late-transient buildup period to evaluate average reservoir pressure, $\bar{P}$ as depicted in Figure 3. The plot should yield a straight line that, when extrapolated to zero, gives an estimate of $\bar{P}$.

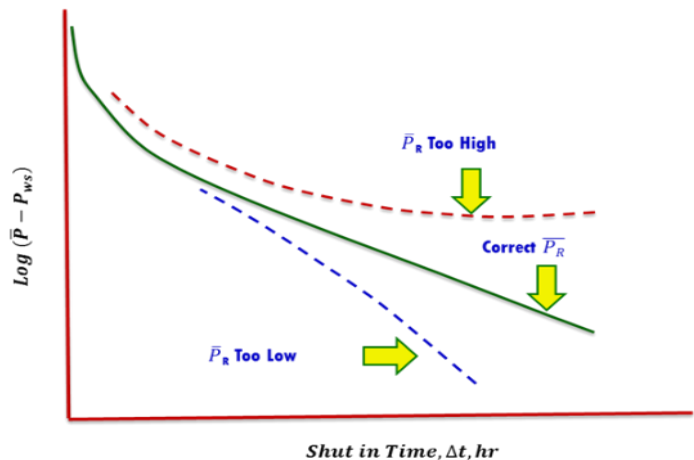

Figure 2 Muskat Method for average pressure determination [2].

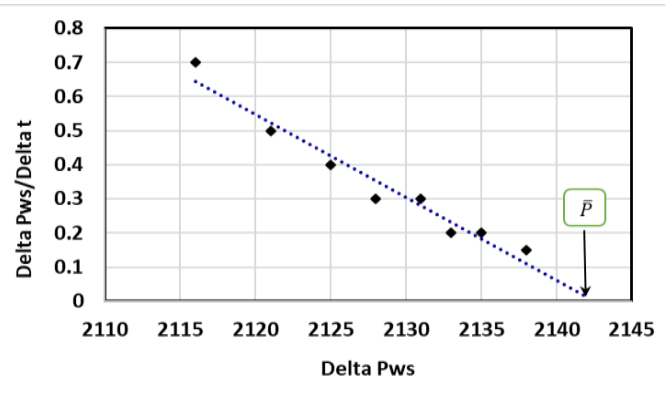

Figure 3 Arps and Smith Method for Av. Pressure estimation[2]

\section{MDH Method:}

In 1950, Miller - Dye - Hutchinson (MDH) [9] presented another method for average reservoir pressure in a closed circular or square drainage regions from the $\mathrm{MDH}$ data plot $\left(P_{w s} S\right.$ versus log $\Delta \mathrm{t}$ ). The MDH method is valid only to wells operating at semi or pseudo-steady state before performing the buildup test. To apply this method, choose any convenient time on the semilog straight line, $\Delta t$, and read the corresponding pressure, $\mathrm{P}_{\text {ws }}$. Then calculate the dimensionless shut-in time based on the drainage area:

$\Delta t_{D A}=\frac{0.0002637 k \Delta t}{B \phi \mu C_{t} A}$

Eqn. 3.

$\bar{P}=P_{w S}+\frac{m P_{D M D H}\left(\Delta t_{D A}\right) \text { upper curve }}{1.1513}$

Eqn. 4

$P_{i}=P_{w S}+\frac{m P_{D M D H}\left(\Delta t_{D A}\right) \text { lower curve }}{1.1513}$

Eqn. 5

Where $\Delta t$ and its corresponding $\mathrm{P}_{\mathrm{ws}}$ are read from the straight-line portion of the MDH plot and $\mathrm{P}_{\mathrm{DMDH}}$ is obtained from $\mathrm{MDH}$ chart in Figure 4.

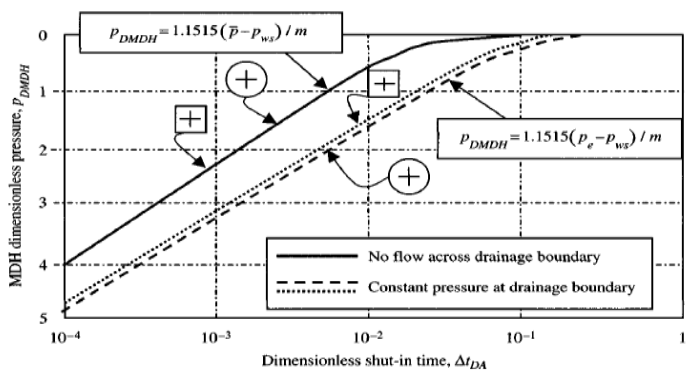

Figure $4 \mathrm{MDH}$ dimensionless pressure for circular and square areas [9] 
4. MBH Method:

In 1954. Matthews, Brons, and Hazebroek (MBH method) [10] presented a method for determination of the average pressure in a bounded reservoir. They mentioned that the reservoir is first allocated into the separate drainage volumes of each well, by using the criterion that at steady state each individual drainage volume is proportional to a well's production rate. The average pressure in each drainage volume is then calculated. By volumetrically averaging these individual drainage volume pressures, the average pressure in the entire reservoir is obtained. For each drainage area, their correction is applied to the ordinary extrapolated pressure, in semi log plot. The correction, which is a function of the production time, is presented in graphical form for different shapes of the drainage area.

The assumptions of using this method are that the reservoir is horizontal, homogeneous, isotropic, and of uniform thickness. The fluid is assumed to be in a single phase of small and constant compressibility and constant viscosity [10].

The $\mathrm{MBH}$ approach is based on theoretical correlations between the extrapolated pressure, $\mathrm{P}^{*}$ (from Horner plot), and average drainage-area pressure, $\bar{P}$, for various drainage-area configurations. This relation is written as follow:

$\bar{P}=P^{*}+\frac{m}{2.303} P_{D M B H}$

Eqn. 6

Where $m$ is the slope of Horner plot, and $\mathrm{P}_{\mathrm{DMBH}}$ is the dimensionless pressure taken from $\mathrm{MBH}$ curves (an example shown in Figure 5 ) by calculating $t_{D A}$.

$t_{D A}=\frac{0.0002637 k t_{p}}{\phi \mu C_{t} A}$

Eqn. 7

The producing time before the test $t_{p}$ is calculated or approximated from the cumulative production and the last producing rate. In principle the results should be identical for any producing time larger than pseudo steady state time $\left(t_{p}>t_{p s s}\right)$ :

$$
t_{p s s}=\frac{\phi \mu C_{t} A}{0.0002637 k}\left(t_{D A}\right)_{p s s}
$$

If $t_{p} \gg t_{p s s}$, then $t_{p s s}$ should be replaced.

From the advantages of this method is that it does not require data beyond the middle time region and can be applied to a wide variety of reservoir drainage areas shapes. While the drawbacks of the $\mathrm{MBH}$ method are the drainage area size and shape must be known and that reliable estimates of rock and fluid properties such as total compressibility $\left(C_{t}\right)$ and porosity $(\phi)$ must be available. Moreover, this method is limited to well tests in single layer formation and cannot be applied accurately to multilayer formations [6].

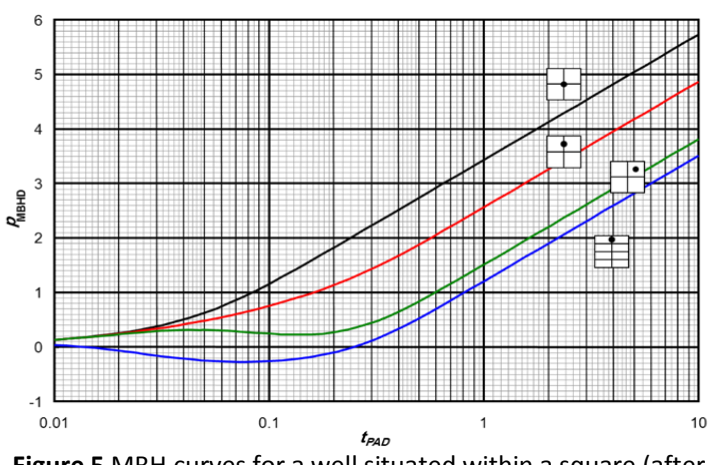

Figure $5 \mathrm{MBH}$ curves for a well situated within a square (after Matthews et al. [10])

\section{Dietz Method:}

In 1965, Dietz [11] used MDH plot to determine the average reservoir pressure in the drainage area. This method gives an accurate result for oil wells with negative skin factor $(S<-3)$ created by matrix acidizing or hydraulic fracturing. The well should be in pseudosteady state before shut-in. Dietz determined the time, $(\Delta t)_{\bar{P}}$, when $\bar{P}$ may be read directly from the extrapolated semi log straight line:

$$
(\Delta t)_{\bar{P}}=\frac{t_{p}}{C_{A} t_{p D A}}=\frac{\phi \mu C_{t} A}{0.000264 C_{A} k} h
$$

Where $C_{A}$ is the Dietz shape factor. This method is very simple and quick [2].

\section{Ramey - Cobb Method:}

In 1971, the Ramey-Cobb [12] also used the shape factor $C_{A}$ while calculating the average reservoir pressure. This method is used to extrapolate a Horner straight line to $\bar{P}$ instead of an $\mathrm{MDH}$ straight line. For $t_{p}>t_{p s s}$ they showed that:

$$
\left[\frac{t_{p}+\Delta t}{\Delta t}\right]_{P_{w s}=\bar{P}}=C_{A} t_{p D A}=\frac{0.0002637 k t_{p} C_{A}}{\varphi \mu C_{t} A} \text { Eqn. } 10
$$

Comparison: Of course, it is not important for all the previous methods to give the same results. This is because each method has its own assumptions and domain of application. Therefore, Table 1 summaries the differences among all of them.

This work is considered an updated version of a previously published paper in journal of Petroleum and Mining Engineering (IPME) 2016 [13].

\section{Egyptian Field Examples:}

\section{Case I: Pressure buildup test}

In an Egyptian oil field, a pressure buildup test was performed in July 2007 in a well having a total depth of $6371 \mathrm{ft}$ in Bahariya formation. The oil well was producing about 203 bpd with nil water cut. Hydraulic fracturing was applied to that well in order to increase the well productivity in September 2007. The production rate increased to about 860 bpd with no water cut. The average reservoir pressure was measured to be 2275 psi. The data is recorded and plotted as shown in Figure 6 . The test duration was about 43 hours. It includes a flow test with two different chock sizes (32 and 64) followed by a pressure buildup for about 25 hours. 
Table 1 Assessment of the average reservoir pressure methods.

\begin{tabular}{|c|c|c|}
\hline Method/Year & Accurate at & Comments \\
\hline $\begin{array}{l}\text { Horner } \\
\text { Method/1951 }\end{array}$ & - A newly or extrapolated wells & $\begin{array}{l}\text { - It gives the initial reservoir } \\
\text { pressure }\end{array}$ \\
\hline $\begin{array}{l}\text { Modified } \\
\text { Muskat } \\
\text { Method/1949 }\end{array}$ & 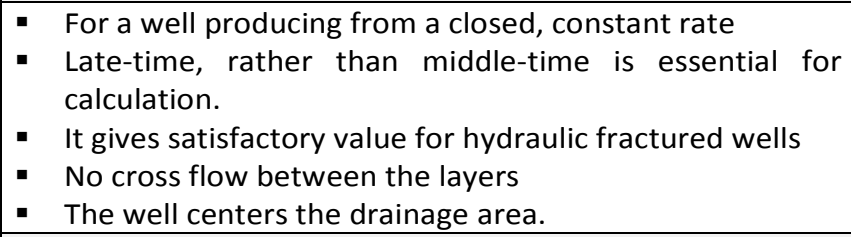 & - It is quite sensitive \\
\hline $\begin{array}{l}\text { Arps and Smith } \\
\text { Method/1949 }\end{array}$ & - It applied during the late-transient buildup period & \\
\hline $\begin{array}{l}\text { MDH } \\
\text { Method/1950 }\end{array}$ & $\begin{array}{l}\text { - It applied for a closed circular or square drainage regions } \\
\text { - Wells operating at semi or pseudo-steady state before } \\
\text { performing the buildup test. }\end{array}$ & $\begin{array}{l}\text { - Uses MDH plot which is } \\
\text { Pws vs. } \Delta \text { t. }\end{array}$ \\
\hline $\begin{array}{l}\text { MBH } \\
\text { Methods/1954 }\end{array}$ & $\begin{array}{l}\text { - The reservoir is horizontal, homogeneous, isotropic, and } \\
\text { of uniform thickness } \\
\text { - The fluid is assumed to be in a single phase of small and } \\
\text { constant compressibility and constant viscosity } \\
\text { - It does not require data beyond the middle time region } \\
\text { and can be applied to a wide variety of reservoir drainage } \\
\text { areas shapes. } \\
\text { - Limited to well tests in single layer formation and cannot } \\
\text { be applied accurately to multilayer formations. }\end{array}$ & $\begin{array}{l}\text { - Drainage area size and } \\
\text { shape must be known and } \\
\text { that reliable estimates of } \\
\text { rock and fluid properties } \\
\text { such as Ct and } \phi \text { must be } \\
\text { available. }\end{array}$ \\
\hline $\begin{array}{l}\text { Dietz } \\
\text { Method/1965 }\end{array}$ & $\begin{array}{l}\text { - It gives accurate results for oil wells with negative skin } \\
\text { factor }(S<-3) \\
\text { - The well should be in pseudo-steady state before shut-in. }\end{array}$ & $\begin{array}{l}\text { - This method is very simple } \\
\text { and quick }\end{array}$ \\
\hline $\begin{array}{l}\text { Ramey - Cobb } \\
\text { Method/1971 }\end{array}$ & $\begin{array}{ll}\text { - } & \text { It requires CA } \\
\text { - } & \text { It uses Horner Plot }\end{array}$ & - It is very simple and quick \\
\hline
\end{tabular}

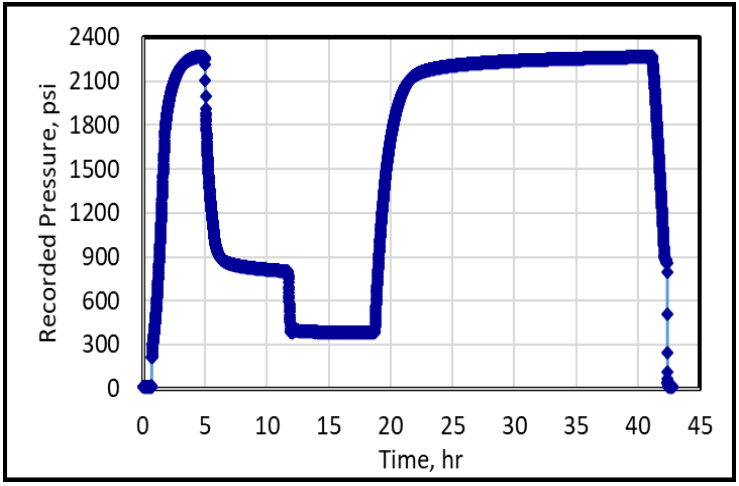

Figure 6 Pressure vs. time for the Case I.

In this example, the average reservoir pressure in the drainage area is calculated by all possible methods. First, these data will be analyzed by using Horner approximation. In this well, the previous producing time was about 17 hours, i.e. $t_{p}=17$ hours. The Horner plot is plotted and presented in Figure 7.

As shown in Figure 7, the extrapolated pressure is 2301.7 psi. Since this test was performed in a well which was explored recently, so one can say the extrapolated pressure is equal the initial average reservoir pressure. Therefore, the average reservoir pressure will be calculated by the other method and so, this fact may be confirmed or not.

\section{Modified Muskat Method}

In this method a guess of several values for the pressure and will be made by plotting Log $\left(\bar{P}-\mathrm{P}_{\mathrm{ws}}\right)$ vs. $\Delta \mathrm{t}$, and next step is to investigate the straight line. The proposed pressure values are 1800, 2100, 2200, 2250,
$2270,2285,2300,2600$, and 2900 psi. The results after proposing these values are depicted in Figure 8. The criteria here is that the plotted line may be concave upward if the assumed pressure is higher than the actual pressure, or downward if the assumed pressure is lower than that of the actual reservoir pressure and it will be straight line in case of assumed pressure is equal the actual pressure. So, as shown in Figure 8 , the straight line is achieved only when the assumed pressure is 2285 psi compared to the real reservoir pressure which is $2275 \mathrm{psi}$. This value is very sensitive because some of the assumptions of Muskat not been achieved. From these assumptions, we are not sure about the position of this data where they are in middle or late time. The centricity of the well location, and the hydraulic fracturing is performed in September 2007 after performing the test.

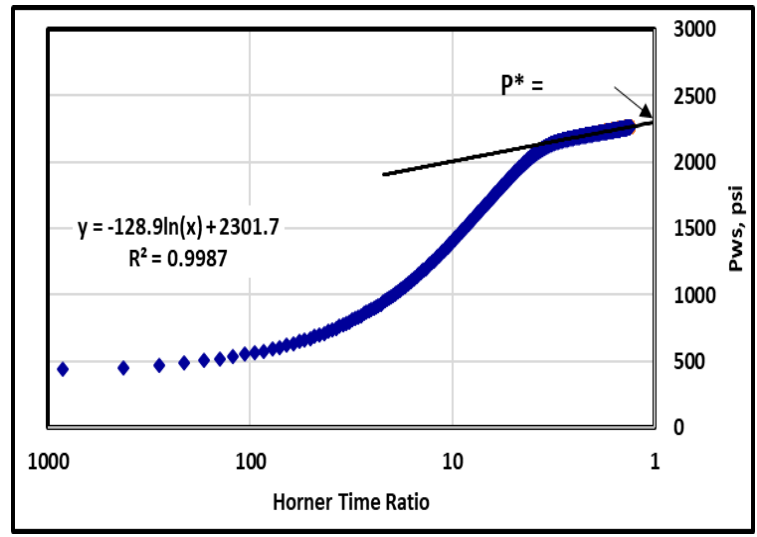

Figure 7 Horner semi log plot for Case I. 


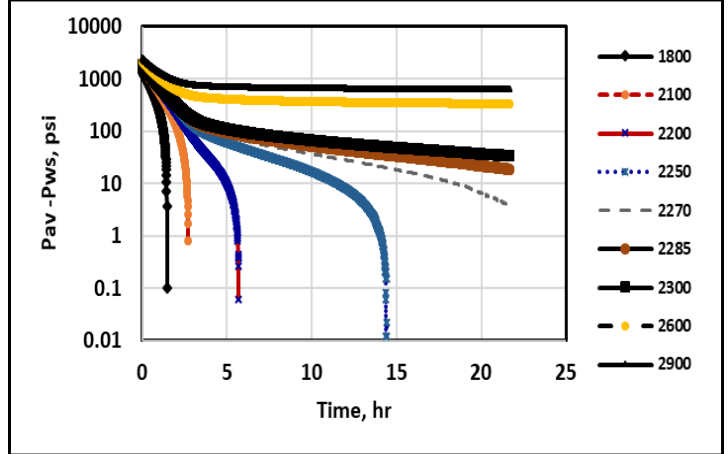

Figure 8 Modified Muskat method for Case I.

\section{Arps and Smith Method:}

In this method, a plot of of $\partial \mathrm{P}_{\mathrm{ws}} / \partial \mathrm{t}$ versus $\mathrm{P}_{\mathrm{ws}}$ is shown in Figure 9. As illustrated in the figure, the average reservoir pressure is 2227.42 psi. It is a little bit lower than that obtained from Muskat extended method. An explanation to method is that this is very sensitive to the test domain which should be in late transient period, and since this test is done at the beginning of the production, and it is probable that the test was performed in the middle time region. Therefore, the accuracy of this pressure is very little minimal. This is confirmed when compared with the real (measured or actual) reservoir pressure which is 2275 psi.

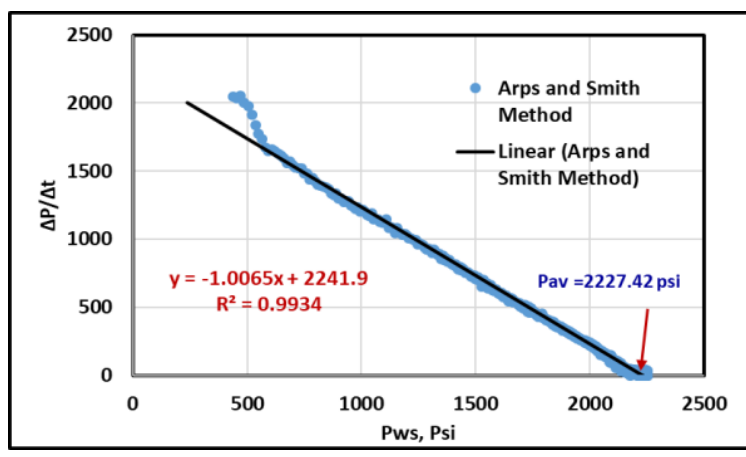

Figure 9 Arps and Smith Method for Case I.

\section{MDH Method:}

In this method, $P_{w s}$ is plotted versus $\log \Delta t$ and the slope of the line is calculated as shown in Figure 10. The slope $(\mathrm{m})$ of this line is equal to $100.69 \mathrm{psi} / \mathrm{cycle}$. The $P_{w s}$ equals 2255.93 psi at $16.6667 \mathrm{hr}$. Using Equation 3 to calculate $\Delta \mathrm{t}_{\mathrm{DA}}$ :

$$
\Delta t_{D A}=\frac{0.0002637 k \Delta t}{B \phi \mu C_{t} A}=0.0030
$$

From MDH chart, $\mathrm{P}_{\mathrm{DMDH}}=0.40$

Then, average reservoir pressure is calculated as follows:

$$
\begin{aligned}
& \bar{P}=P_{w S}+\frac{m P_{D M D H}\left(\Delta t_{D A}\right) \text { upper } \text { curve }}{1.1513}=2255.93+ \\
& (100.69 * 1.30) / 1.1513=2323.20 \mathrm{psi}
\end{aligned}
$$

As shown, this value is comparable to the pressure calculated from previous methods. This value is considered a little bit accurate because all assumptions of this method are applied except the accuracy of the reservoir area that has been calculated by the volumetric method as $50343148.395 \mathrm{ft}^{2}$ and the period of well testing duration.
MBH Method:

In this method, the slope of Horner plot is required and so it is picked from the semi-log plot of Horner and it is found equal to $296.86 \mathrm{psi} / \mathrm{cycle}$. To also require calculating $\mathrm{P}_{\mathrm{DMBH}}$ based on the dimensionless time as follows:

$$
\begin{aligned}
& t_{D A}=\frac{0.0002637 k t_{p}}{\phi \mu C_{t} A}=0.0043 \\
& \text { So: } \\
& \bar{P}=P^{*}+\frac{m}{2.303} P_{D M B H}=2301.7 \mathrm{psi}
\end{aligned}
$$

This value is playing around the other values obtained from the other methods

\section{Dietz Method:}

By assuming a circular reservoir so the shape factor CA is about 31.62. The time of average reservoir pressure is calculated by:

$$
(\Delta t)_{\bar{P}}=\frac{t_{p}}{C_{A} t_{p D A}}=\frac{\phi \mu C_{t} A}{0.000264 C_{A} k} h=5278.539 \mathrm{hrs}
$$

Then Horner Time Ratio $(\mathrm{HTR})=1.0003226$

By extrapolating the straight line on Horner plot, then the pressure is:

$$
\bar{P}=2301.285 \text { psi }
$$

By assuming a square reservoir shape, i.e. $C A=$ 30.8828 , so the $\bar{P}=2301.30 \mathrm{psi}$

\section{Ramey - Cobb Method}

The calculated Horner time ratio (HTR) that met the average pressure is about 0.1930 and 0.1946 for circular and square reservoir shape, respectively. Therefore, from semi log plot of Horner, the pressures are 2513.74 psi for a circular reservoir shape and 2512.67 psi for the square reservoir shape.

Table 2 listed all the previous results for all methods used for average reservoir pressure determination.

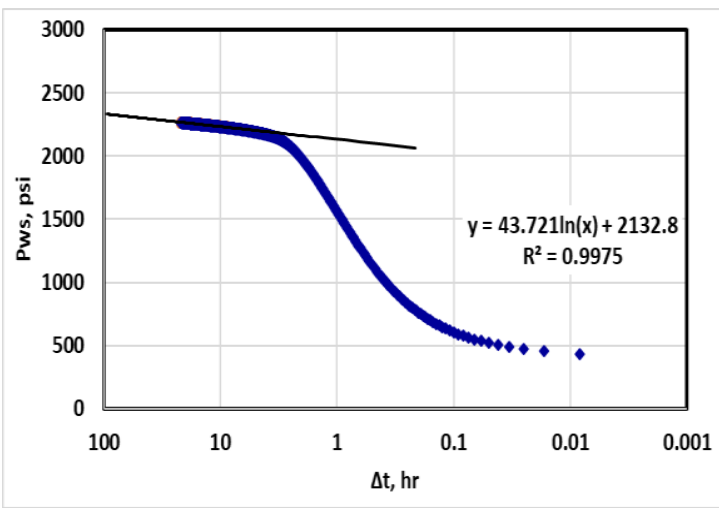

Figure $10 \mathrm{MDH}$ Plot for pressure buildup Case I.

Table 2 Statistical analysis for average pressure

\begin{tabular}{l|l|l}
\multicolumn{3}{c}{ methods for Case I. } \\
\hline Method & $\begin{array}{l}\text { Average } \\
\text { Pressure } \\
\text { Values }\end{array}$ & $\begin{array}{l}\text { Deviation, } \\
\%\end{array}$ \\
\hline Horner Method & 2301.7 & 1.174 \\
\hline $\begin{array}{l}\text { Modified Muskat } \\
\text { Method }\end{array}$ & 2285 & 0.440 \\
\hline $\begin{array}{l}\text { Arps and Smith } \\
\text { Method }\end{array}$ & 2275 & 0.000 \\
\hline MDH Method & 2323.20 & 2.119 \\
\hline MBH Methods & 2301.7 & 1.174 \\
\hline Dietz Method & 2301.285 & 1.155 \\
\hline Ramey - Cobb Method & 2513.74 & 10.494 \\
\hline
\end{tabular}


As illustrated in Table 2, most accurate method for this case (Case I) is Arps and Smith method, followed by Modified Muskat, then $\mathrm{MBH}$ and Horner Method. Horner method is giving a considerable result because this test is performed immediately after production start-up. Dietz and MDH are giving a moderate result but the worst method in this case is Ramey-Cobb method.

\section{Simulation study for Case I:}

Using Saphir Kappa (Ecrin version v4.02.04)[14], this case is simulated and the results are shown in Figure 11.

As shown from the results on the top right of the Figure 11, the initial pressure is 2307.92 psia (2293.19 psi). This value is a little bit higher than the actual one. The error percentage is $0.799 \%$.

This case simulated with best match we can get since I tried so many models in the software itself. So what has been obtained here is the best although the matching is not achieved in the pressure derivative curve in transient period as it should be. But what has been noticed when I change the model and the other parameters that control the matching and improve the obtained results, the pressure value does change a lot. So I consider this result is satisfactory result for the case.

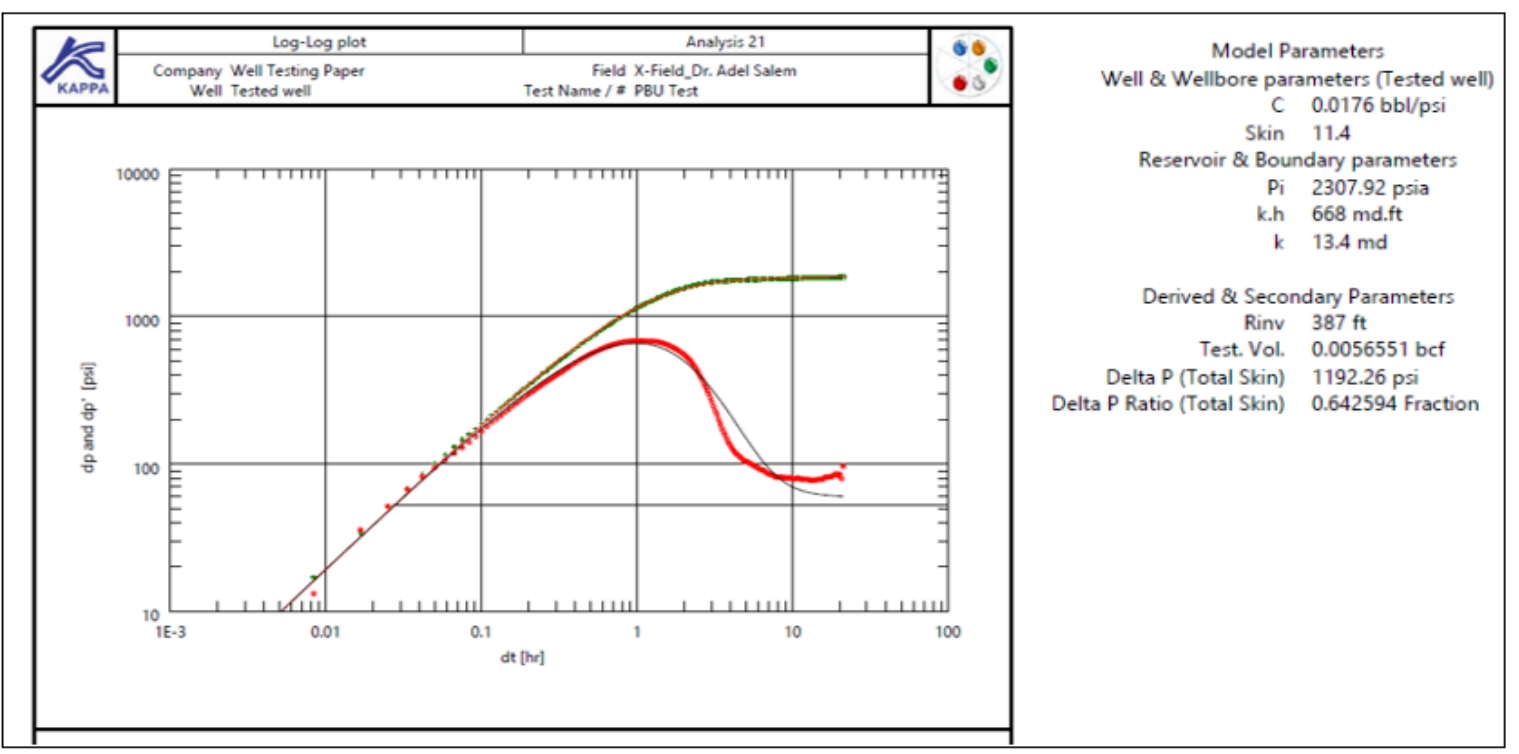

Figure 11 Saphir simulation study for Case I.

\section{Case II:}

A pressure buildup test was performed in XD-1 Well in an Egyptian oil field discovered in 1978 and commenced production on 1983. The reservoir is relatively deep massive Nubian sandstone. The oil water contact (OWC) at that time is located at 12350 $\mathrm{ft}$. it has 16 producers and 3 injectors over three offshore platforms. The major faults divided the reservoir into three main blocks $A, B$, and $C$ each one is dipping NNE.

In 1991 a pressure build up was performed in the well XD-1, and the pertinent PVT data and well data are as follows:

$$
\begin{aligned}
& \mathrm{C}_{o}=1.376 \mathrm{E}-5 \mathrm{psi}-1 \\
& \mathrm{Bo}=1.181 \mathrm{RB} / \mathrm{STB} \\
& \mu \mathrm{o}=2.256 \mathrm{cp} \\
& \mathrm{r}_{\mathrm{w}}=0.354 \mathrm{ft} \\
& \mathrm{h}=352.0 \mathrm{ft} \\
& \mathrm{Cr}=4.19 \mathrm{E}-6 \mathrm{psi}-1 \\
& \mathrm{~S}_{\mathrm{w}}=0.03 \\
& \mathrm{CW}_{\mathrm{w}}=3.60 \mathrm{E}-06 \mathrm{psi}-1
\end{aligned}
$$

The following section will describe each method for average reservoir pressure determination as in Case I. The recorded test data is plotted as shown in Figure 12.

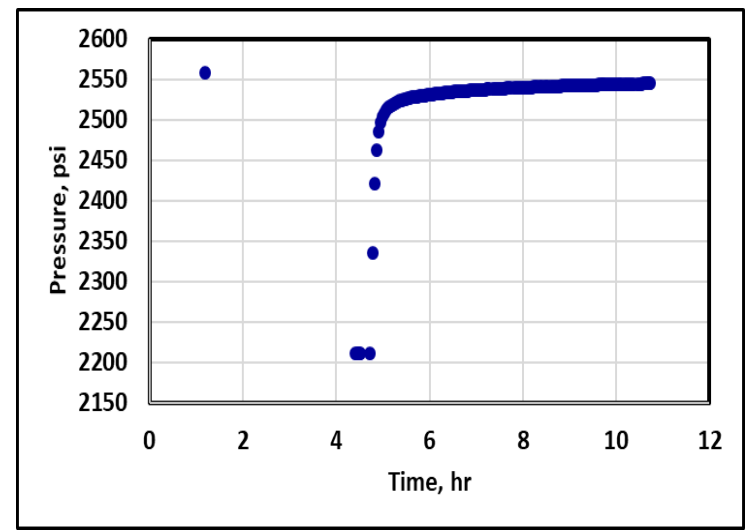

Figure 12 Pressure vs. time for case II

\section{Horner Method:}

Based on the Horner plot, the slope of the line was calculated as about $22 \mathrm{psi} / \mathrm{cycle}$ and the intercept which gives the false (approximate) reservoir pressure is about 2636 psi as shown in Figure 13. 


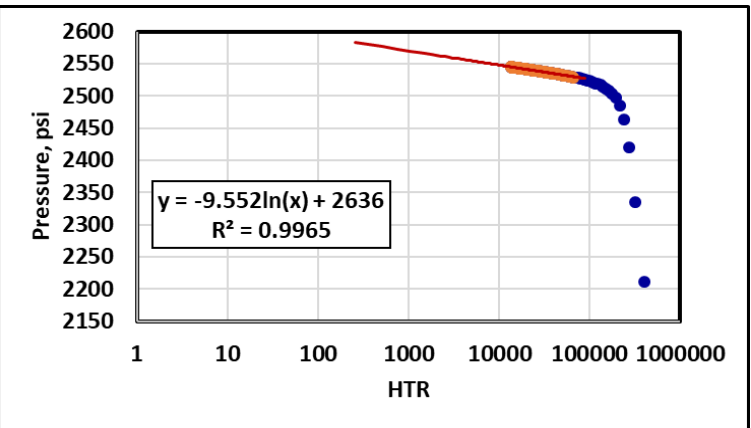

Figure 13 Horner Plot of Case II in this Study of well XD-1.

\section{Modified Muskat Method}

Several pressure values are assumed and $\log (\bar{P}$ $\left.P_{w s}\right)$ vs. $\Delta t$ is plotted. These values are 2500,2525 , $2530,2540,2545,2550,2560,2575,2600,2700,2800$, and 2900 psi. The results are shown in Figure 14.

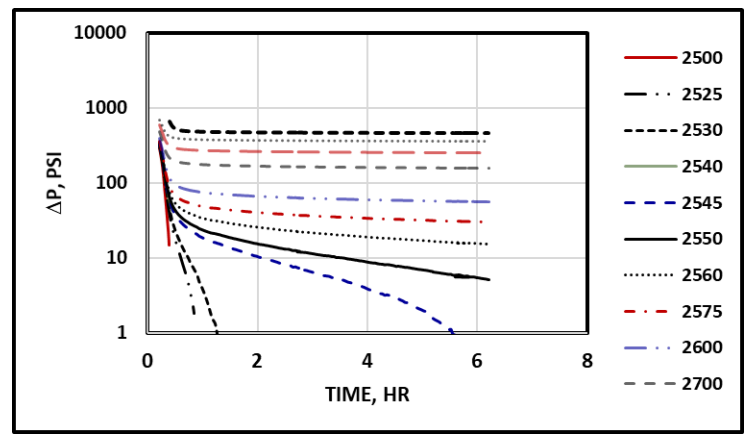

Figure 14 Muskat method for Case II.

After investigating the previous cuves, it is found that the straight line can be achieved if the assumed pressure ranges between 2545 psi and 2550 psi so the average reservoir pressure can be approximated at about 2447.5 psi.

\section{Arps and Smith Method:}

The average pressure calculated by this method is 2538.215 psi as shown in Figure 15.

\section{MDH Method:}

By performing the same calculation (see Figure 16) as in case I, the pressure value is found to be is 2652.358 psi.

\section{MBH Method:}

In this method, the slope of Horner plot is required and so it is selected from the semi log plot of Horner, and it is found equal to $22 \mathrm{psi} / \mathrm{cycle}$. To also require calculating $\mathrm{P}_{\mathrm{DMBH}}$ based on the dimensionless time as follows:

\section{$\bar{P}=2691.4016 \mathrm{psi}$}

\section{Dietz Method:}

By the same procedures done before for Case I, the average pressure is found to be: 2621.5 psi.

\section{Ramey - Cobb Method}

The calculated Horner time ratio (HTR) that met the average pressure is about 394.1619 and 397.44 for circular and square reservoir shape respectively. Therefore, from semi log plot of Horner, the pressures are 2578.91 psi for a circular reservoir shape and2578.83 psi for the square reservoir shape.
Table 3 listed all the previous results for all methods used for average reservoir pressure determination.

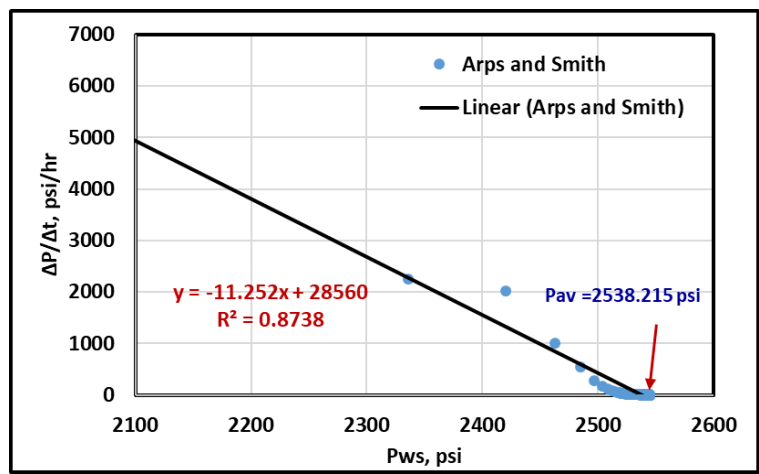

Figure 15 Arps and Smith Method for Case II.

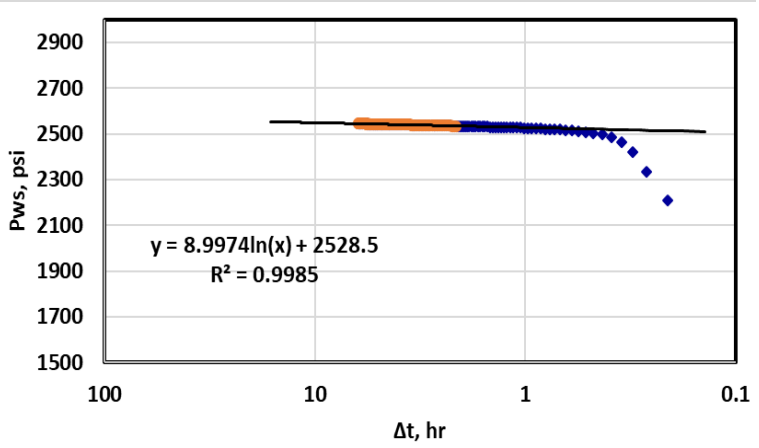

Figure $16 \mathrm{MDH}$ Plot for Case II

Table 3 Statistical analysis for average reservoir pressure methods for Case I.

\begin{tabular}{|c|c|c|}
\hline Method & $\begin{array}{c}\text { Average } \\
\text { Pressure Values }\end{array}$ & \% Error, \\
\hline Horner Method & 2636 & -5.86 \\
\hline $\begin{array}{l}\text { Modified Muskat } \\
\text { Method }\end{array}$ & 2447.5 & -12.59 \\
\hline $\begin{array}{l}\text { Arps and Smith } \\
\text { Method }\end{array}$ & 2538.215 & -9.35 \\
\hline MDH Method & 2652.358 & -5.27 \\
\hline MBH Methods & 2691.4016 & -3.88 \\
\hline Dietz Method & 2621.482 & -6.38 \\
\hline $\begin{array}{l}\text { Ramey-Cobb } \\
\text { Method }\end{array}$ & 2578.91 & -7.90 \\
\hline
\end{tabular}

From these calculations, it is obvious that the best approach is $\mathrm{MBH}$ followed by $\mathrm{MDH}$ and then Horner method. It is also noted that all methods give less pressure values than the actual measured one.

\section{Simulation study for Case II:}

Using Saphir Kappa (Ecrin version v4.02.04) [12][14], this case is simulated and the results are represented in Figure 17.

As shown from the results on the top right of the Figure 17, the initial pressure is 2566.91 psi. This value is a little bit higher than the actual one. The error percentage is $8.32 \%$.

In the second case, I choose a constant wellbore storage as a wellbore model, vertical well, the reservoir is homogeneous, and the boundary model is intersecting faults-Any Angle and the distance to these two faults are $148.319 \mathrm{ft}$ and $170.848 \mathrm{ft}$. the initial pressure calculated by Saphir is about 2566.91 psi. 


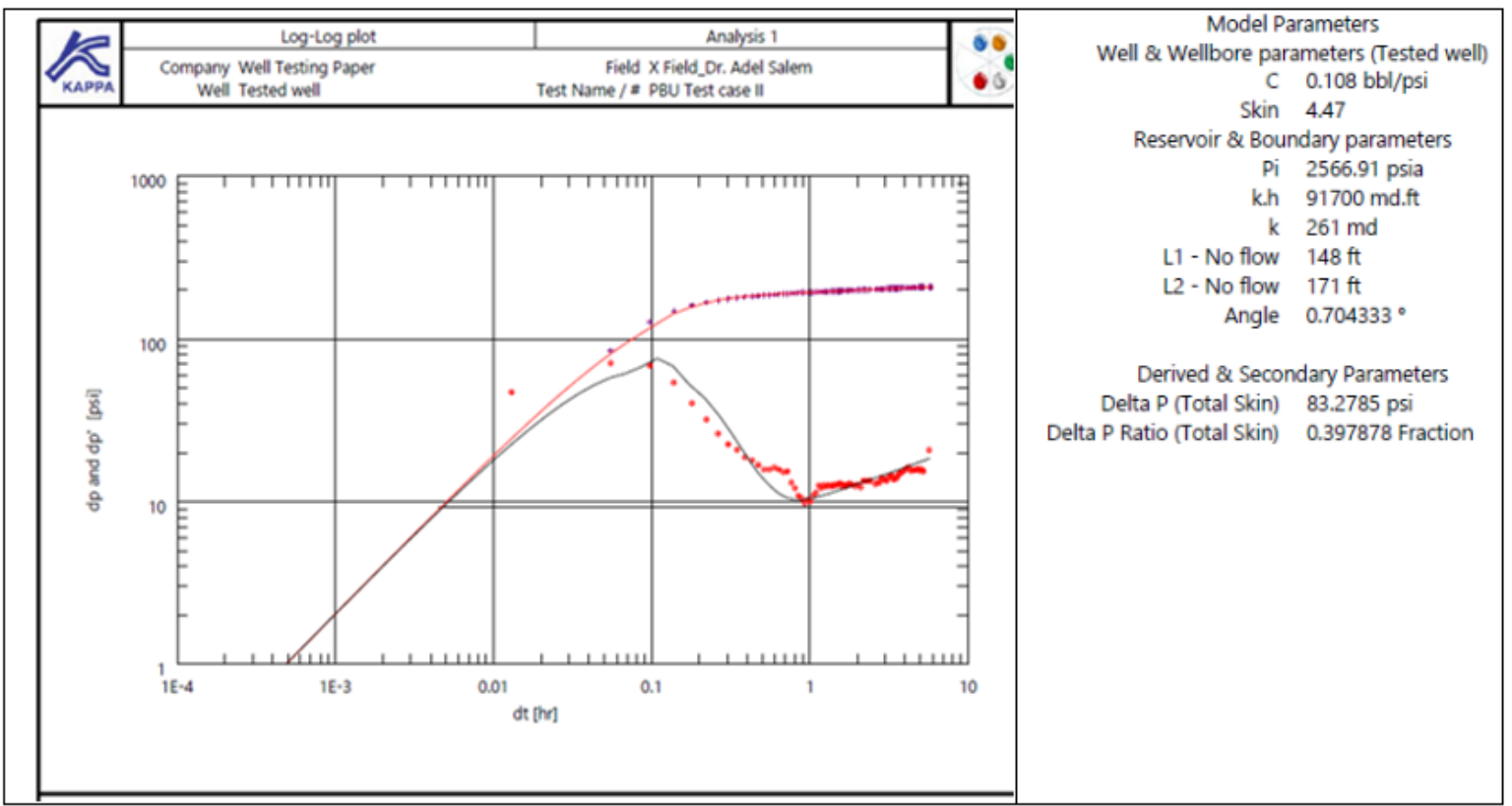

Figure 17 Saphir simulation study for Case II.

\section{Conclusions:}

The following conclusion may be obtained from this study:

1. Average reservoir pressure is crucial in all reservoir calculations current and future.

2. There are a lot of methods used to determine reservoir pressure, but each method has its limitation and so not any one is suitable for any case.

3. $\mathrm{MBH}, \mathrm{MDH}$, and Horner methods are the best method to calculate the reservoir pressure for the Egyptian cases under investigation if the reservoir pressure in the ranges of 2000 to 3000 psi.

4. In case of no faults, the results of most of these methods are more accurate than if faults exist. The error percent does not exceed $2.5 \%$ for most of them but in case of faulted reservoir the error percent ranges from $3.88 \%$ to $12.89 \%$.

5. The cases under study are simulated and analyzed and the results are compared with these obtained from the other analytical methods

6. This study provided the optimum procedures to apply all of reservoir pressure determination methods.

\section{Acknowledgement:}

The author would like to appreciate Dr. Ismail Mahgoub (Petroleum Engineering Department HeadFuture University in Egypt - FUE) for reviewing this paper, his valuable comments and fruitful discussion regarding to the idea. Great appreciation and thanks go to KAPPA Company, the owner of Saphir for their support by donating us a university version.

\section{REFERENCES}

[1]. U. Ahmed, J. L. Hendrix. and B. J. Schwanitz, Use of Transient Rate and Pressure Data to Determine Area Average Reservoir Pressure without Shutting in the Well. Paper SPE 27623 presented at the European Production
Operations Conference and Exhibition, Aberdeen, U. K. 15-17 March 1994.

[2]. A. U. Chaudhry, Oil Well Testing Handbook, Gulf Professional Publishing, 2004.

[3]. T. Ahmed and P. D. McKinney, Advanced Reservoir Engineering, Gulf Professional Publishing, 2005.

[4]. D. R. Horner, Pressure Build-up in Wells, Proceedings Third World Petroleum CongressSection II. Leiden, (1951) 503-521.

[5]. D. R. Horner, Pressure Buildup in Wells, Pressure Analysis Methods, Reprint Series, SPE, Richardson, Texas. 9 (1967) 25-43.

[6]. J. Lee, H. B. Rollins and J. P. Spivey, Pressure Transient Testing, SPE Textbook Series Volume 9, 2003.

[7]. M. Muskat, Physical Principles of Oil Production, McGraw-Hill Book Co, Inc., NY, 1949

[8]. J. J. Arps and A. E. Smith, Practical Use of Bottom-Hole Pressure Buildup Curves, Drill and Prod. Pract. API, (1949) 155-165.

[9]. C. C. Miller, A. B. Dyes and C. A. Hutchinson, The Estimation of Permeability and Reservoir Pressure from Bottom Hole Pressure Buildup Characteristics, Trans. AIME, 189 (1950) 91-104.

[10]. C. S. Matthews, F. Brons and P. Hazebroek, A Method for Determination of Average Pressure in a Bounded Reservoir, Trans., AIME 201 (1954) 182-91.

[11]. D. N. Dietz, Determination of Average Reservoir Pressure from Build- Up Surveys, Trans. AIME, 1965.

[12]. H. J., Jr. Ramey and W. M. Cobb, A General Buildup Theory for a Well in a Closed Drainage Area, J. Pet. Tech. (Dec. 1971) 1493-1505.

[13]. Adel M. Salem. A Comparative Analysis of reservoir Pressure Determination Using Buildup Test: Analytical and Simulation Approach. Journal of Petroleum and Mining Engineering (JPME), ISSN: 1110-6506, 2016.

[14]. Saphir Program: https://www.kappaeng.com/software/saphir/o verview (accessed 15 May 2016). 